\title{
Parental Health Spillover in Cost-Effectiveness Analysis: Evidence from Self-Harming Adolescents in England
}

\author{
Sandy Tubeuf ${ }^{1,2}{ }^{(\mathbb{C}} \cdot$ Eirini-Christina Saloniki $^{3,4} \cdot$ David Cottrell $^{5}$
}

Published online: 8 October 2018

(c) The Author(s) 2018, corrected publication 2019

\begin{abstract}
Objective This article presents alternative parental health spillover quantification methods in the context of a randomised controlled trial comparing family therapy with treatment as usual as an intervention for self-harming adolescents, and discusses the practical limitations of those methods.

Methods The trial followed a sample of 754 participants aged 11-17 years. Health utilities are measured using answers to the EuroQoL 5 Dimensions 3 Levels (EQ-5D-3L) for the adolescent and the Health Utility Index (HUI2) for one parent at baseline, 6 and 12 months. We use regression analyses to evaluate the association between the parent's and adolescent's health utilities as part of an explanatory regression model including health-related and demographic characteristics of both the adolescent and the parent. We then measure cost-effectiveness over a 12-month period as mean incremental cost-effectiveness ratios using various spillover quantification methods. We propose an original quantification based on the use of a household welfare function along with an equivalence scale to generate a health gain within the family to be added to the adolescent's quality-adjusted life-year gain. Results We find that the parent's health utility increased over the duration of the trial and is significantly and positively associated with adolescent's health utility at 6 and 12 months but not at baseline. When considering the adolescent's health gain only, the incremental cost-effectiveness ratio is $£ 40,453$ per quality-adjusted life-year. When including the health spillover to one parent, the incremental cost-effectiveness ratio estimates range from $£ 27,167$ per quality-adjusted life-year to $£ 40,838$ per quality-adjusted life-year and can be a dominated option depending on the quantification method used.

Conclusion According to the health spillover quantification method considered, the incremental cost-effectiveness ratios vary from within the National Institute for Health and Care Excellence (NICE) cost-effectiveness threshold range to not being cost-effective.
\end{abstract}

Sandy Tubeuf

s.tubeuf@leeds.ac.uk; sandy.tubeuf@uclouvain.be

Eirini-Christina Saloniki

e.saloniki@kent.ac.uk

David Cottrell

d.j.cottrell@leeds.ac.uk

1 Academic Unit of Health Economics, University of Leeds, Leeds LS2 9NL, UK

2 Institute of Health and Society, Université Catholique de Louvain, Louvain-La-Neuve, Belgium

3 Centre for Health Services Studies, University of Kent, Kent, UK

4 Personal Social Services Research Unit, University of Kent, Kent, UK

5 Psychological and Social Medicine, University of Leeds, Leeds, UK

\section{Key Points}

Parental health spillover varies with treatment arms and follow-up points, and is independent from the adolescent's health improvement.

Health spillover can be measured using a household welfare function along with an equivalence scale to generate a health gain within the family to be added to the patient's quality-adjusted life-year gain.

According to the health spillover quantification method considered, the incremental cost-effectiveness ratio varies from being cost-effective to not being cost-effective. 


\section{Introduction}

Self-harm is commonly defined in the UK and Europe as any form of non-fatal self-poisoning or self-injury (such as cutting, taking an overdose, hanging, self-strangulation, jumping from a height and running into traffic), regardless of the motivation or degree of intention to die. This definition would include US definitions of non-suicidal self-injury and suicidal behaviour. Self-harm in adolescents is a major public health issue with one in ten adolescents self-harming each year [1]. Individuals with mental disorders are heavy users of public health services and require emotional support and care from their family [2,3]. Their disorders are likely to affect other family members' health and own healthcare needs, especially because individuals with mental health conditions face elevated rates of all-cause mortality and this places a huge burden of costs and life-years lost on the family and the community [4].

It appears that the magnitude of spillovers on the health of other family members is the greatest in parents of ill children $[5,6]$. Beyond the effect of caring for an ill child on parents' health [7], treatments that are provided to a selfharming child may have various spillover effects for the family. Indeed, psychotherapeutic treatments such as familybased therapies are often used with self-harming adolescents; they rely on individuals' relational network, involve parents, caregivers, brothers and sisters, or other close relatives and friends in the therapies to improve clinical outcomes [8], and typically aim at maximizing cohesion, attachment and support while moderating parental control [9]. Therapy sessions do not necessarily include all family members, but it is expected that they will have an impact beyond the identified patient.

Some prior economic evaluations of psychotherapeutic interventions in young people have examined the impact of the therapy on the adolescent/child patient and on relatives participating in the therapy. These studies collected parents or carers' outcomes and used them as additional outcomes of interest in a cost-effectiveness analysis (CEA) [10-12], whilst only two studies combined child and parents' outcomes. Bodden et al. [13] used a compound summary of anxiety-specific scores of the child, mother and father, as part of the sensitivity analyses. Their analysis measured the cost-effectiveness per anxiety-free family by including the costs related to the child and other family members' anxiety as self-reported in cost diaries. Cottrell et al. [14] used the same data as this article over an 18-month follow-up and aggregated quality-adjusted life-years (QALYs) of the adolescent and one parent as a sum in a sensitivity analysis. Their application relied on the strong assumption that QALYs can be summed across individuals. This assumption has been used in other studies in child health [15] and is consistent with research showing benefits to other family members involved in mental health family treatment $[16$, 17]. However, such considerations require a more thorough discussion of the interdependence between the utility functions of the adolescent and the parent, and the most appropriate method to include the overall health benefits.

The National Institute for Health and Care Excellence (NICE) reference case underlines that the perspective on outcomes considers "all direct health effects, whether for patients or, when relevant, carers" [18]; however, there is no consensus on how these health effects should be measured and valued. Wittenberg and Posser [19] offered a summary of the evidence on the measurement and incorporation of health spillover of illness on family members or caregivers across health conditions, as a disutility. In their review, methods to measure spillovers included three different types: (1) a direct measure of disutility of family members; (2) a relative measure of family members' utility with a comparison to a control group; or (3) an estimation of the utility of family members in a hypothetical scenario in which the patient is healthy or does not require caregiving.

In empirical economic evaluation studies, health spillovers have been included either as accrued health benefits [20-22] or as an estimated multiplier parameter, which adjusts the patient's health gain with a spillover for the rest of a wider network (including parents, carers, spouses and other relevant individuals) [23, 24]. Whilst the first method uses a health-related quality of life (HRQoL) questionnaire and directly elicited utilities, the multiplier effect is based on a regression model using observational or primary data collection and consists of two multiplier effects.

In this article, we use data from a multi-centre, individually randomised controlled trial comparing family therapy (FT) with treatment as usual (TAU) as an intervention for self-harming adolescents aged 11-17 years [25] as a case study. Both the adolescent and one parent ${ }^{1}$ reported their HRQoL as part of the trial across repeated follow-up points. We undertake a within-trial CEA incorporating parental health spillover effects using alternative quantification methods. We add to the growing literature in three ways. First, we investigate the association between the health utility of the parent and a self-harming adolescent as part of an explanatory regression model using the preference-based HRQoL scores of both the adolescent and one parent. Second, we present a comparative analysis of alternative spillover quantification methods as part of an economic evaluation, bringing together the dyadic and the regression-based perspectives. Finally, we discuss how health spillovers could be adjusted including benefits to the rest of the family using an equivalence scale (ES) to adjust parental health gain.

\footnotetext{
1 The study collected data on the main caregiver, who was either the mother $(86 \%)$ or the father (11\%), thus we loosely use the term parent in this article.
} 
Table 1 Description of clinical scores

Adolescent Hopelessness Scale for Children: A measure of the degree to which adolescents have negative expectancies about themselves and the future. It consists of 17 items with true or false responses, providing a single overall score with higher scores reflecting greater negative expectations towards the future

Parent Family Questionnaire: A 20-item self-report questionnaire relating to the different ways in which families try to cope with everyday problems. It consists of a single overall score with higher scores indicating greater levels of expressed emotion directed at the adolescent by the parent

McMaster Family Assessment Device: A measurement of family functioning across 60 items on six different dimensions: Problem Solving, Communication, Roles, Affective Responsiveness, Affective Involvement and Behaviour Control. A higher total score is indicative of poorer family functioning

GHQ-12: A measure of current mental health focusing on two major areas: the inability to carry out normal functions and the appearance of new and distressing experiences. High total scores are indicative of greater psychological distress

GHQ General Health Questionnaire

\section{Self-Harm Intervention: Family Therapy (SHIFT) Trial Case Study}

The self-harm intervention: family therapy (SHIFT) study was a randomised controlled trial conducted in local child and adolescent mental health services in Yorkshire, Greater Manchester and London for adolescents aged 11-17 years who had self-harmed twice. Participants were randomly allocated to receive FT or TAU. The objective of the trial was to assess whether FT would reduce the number of times the adolescents attended hospital with further self-harm. The trial results are reported elsewhere [14].

Personal characteristics were collected at baseline including the adolescent's sex, age, and type and number of selfharm episodes, as well as the sex and age of their parent. Additional information was collected on the adolescent's mental health using the Hopelessness Scale for Children [26], the parent's emotion toward the adolescent using the Family Questionnaire [27], the parent's viewpoint on the family atmosphere through the McMaster Family Assessment Device [28] and the parents' General Health Questionnaire (GHQ-12) [29]. All these measurements are defined in Table 1. The adolescent's HRQoL was measured by the EuroQoL 5 Dimensions 3 Levels (EQ-5D-3L) [30] whilst the parent's HRQol was determined by the Health Utility Index (HUI2) $[31,32]$. The original research proposal considered HUI2 as the HRQoL measure for both the parent and the adolescent following the NICE guidelines at the time [33, 34]. However, we carried out a pilot study [35] on a sample of 49 adolescents aged 11-18 years to test the ability of children to deal with the concepts and language used in the EQ-5D-3L and HUI2. We found that EQ-5D-3L had the least amount of missing data and presented limited problematic wording for that age group; therefore, the EQ-5D-3L was eventually used to measure the HRQoL of adolescents in the trial. However, the parents' HRQoL instrument was not changed.

An adolescent's responses to the EQ-5D-3L were converted into health-state utility scores using national tariff values [36]. Similarly, a parent's responses to HUI2 were converted into health-state utility values [32, 37]. The area under the curve approach was used to calculate QALYs for the adolescent and the parent.

Resource use of health services was self-reported by the adolescent and/or his or her parent. Accident and emergency visits and inpatient stays of the adolescent were available from National Health Service digital records. Resource use was combined with national unit costs distinguishing, where possible, by a self-harm and not self-harm-related event leading to hospitalisation [38]. Psychotropic medication costs were calculated using trial medication records. The intervention costs were calculated separately for each treatment arm using information on the type and duration of the therapies sessions available from the trial records $[14,39]$.

Eight hundred and thirty-two adolescents and their parents were recruited in the trial (417 in TAU and 415 in FT). This article focuses on the first 12-month follow-up, thus discounting is not required. Missing utility scores and total health and hospital services costs at 6 and 12 months were imputed using multiple imputations via chained equations [40-42]. Imputations were based on a number of demographic and clinical predictors; the process is described elsewhere [39]. Missing utility (4\%) and clinical scores (3\%) at baseline were not imputed. The sample used in the main analysis is 731 adolescents and their parent (359 in TAU and 372 in FT). As part of the sensitivity analysis, the analysis was also carried out on the complete case sample; the sample reduced to 206 adolescents and their parent (73 in TAU and 133 in FT).

\section{Methods}

\subsection{Association Between a Parent's and a Self-Harming Adolescent's Health}

We first modelled the utility of the parent as a function of the adolescent's HRQoL (utility) in the same period controlling for a number of adolescent and parent characteristics. 
There is no reason to believe that this association remains consistent over time; therefore, our approach extends prior research $[7,23]$ by investigating the relationship empirically at multiple follow-up points in the data as follows:

$H_{i}^{t}=a^{t}+\beta_{1}^{t} H_{j}^{t}+\beta_{2}^{t} Z_{j}^{0}+\beta_{3}^{t} C_{i}^{0}+\varepsilon_{i}^{t}$,

where $H_{i}^{t}$ denotes the parent's $i$ health-related quality of life measured by the HUI2 index score at time $t=0,1,2$ for baseline, 6 and 12 months; $H_{j}^{t}$ denotes the adolescent's $j$ HRQoL at time $t$ measured by the overall EQ-5D-3L index score; $Z_{j}^{0}$ is a vector of baseline characteristics of the adolescent such as age, sex, type of self-harm event and total number of self-harm events; $C_{i}^{0}$ is a vector of baseline characteristics of the parent such as sex and mental health measured by the GHQ-12; $\alpha^{t}$ is the intercept, $\beta_{1}^{t}, \ldots, \beta_{3}^{t}$ are the slope parameters and $\varepsilon_{i}^{t}$ is the error term with $\varepsilon_{i}^{t} \sim N(0,1)$. The distribution of the utility of the parent is skewed to the left, thus we estimate all regression models using Tobit models.

The estimated coefficients were similar to those from the ordinary least-squares regressions both in magnitude and sign. We initially ran Model 1 including demographic controls for both the adolescent (age, sex) and the parent (age). To account for the heterogeneity observed in adolescents' parents, we subsequently ran Model 2 controlling for other adolescent characteristics (Hopelessness Scale for Children score, type of self-harm) and family characteristics from the parent's perspective (Family Questionnaire, McMaster Family Assessment Device) as well as the parent's GHQ-12. We supplemented this simplistic association analysis with a more causal understanding of the impact of a positive change in the adolescent's health over time on a parent's HRQoL in line with Bhadhuri et al. [43]. We included a binary variable, taking the value 1 if the adolescent's EQ-5D-3L score improved between baseline and follow-up, but this parameter was not significant and did not impact on the results. ${ }^{2}$

\subsection{Parental Health Spillover in Cost-Effectiveness Analysis: Five Alternative Quantifications}

The base-case CEA considers the incremental costs and QALYs associated with FT vs. TAU as an intervention for self-harming adolescents. We are interested in quantifying the health spillover effects to the parent in the CEA, which can be used as an extra QALY gain inflating the adolescent's QALY gain. Using the regression model presented in Eq. (1) as a starting point, we suggest four alternative quantification methods to evaluate parental health spillover. We also consider a fifth quantification with a direct measurement of parental QALY gain using answers to the HUI2 index.

\footnotetext{
2 Results available upon request.
}

\subsubsection{Relative Health Spillover (Quantification 1)}

The estimated parameter $\widehat{\beta}_{1}^{t}$ in Eq. (1) can be used to extract a spillover coefficient of an adolescent's health utility on parents. Assuming policy makers are interested in accounting for broad health benefits independently of the treatment arm, the parameters $\widehat{\beta_{1}^{0}}, \widehat{\beta_{1}^{1}}$ and $\hat{\beta}_{1}^{2}$ represent a utility gain for the parent at each time point, which can be transformed into a QALY gain using the area under the curve approach as follows:

$\operatorname{QALY}_{i}^{\mathrm{Spe} 1}=\left[\frac{\left(\widehat{\beta_{1}^{0}}+\hat{\beta}_{1}^{1}\right)}{2}\right] \times 0.5+\left[\frac{\left(\hat{\beta}_{1}^{1}+\hat{\beta}_{1}^{2}\right)}{2}\right] \times 0.5$.

If the relationship between the adolescent's and parent's HRQoL remains constant over time, the parameter $\widehat{\beta}_{1}^{t}$ represents the full QALY gain, which is similar to what Al-Janabi et al. [24] called relative spillover.

\subsubsection{Relative Health Spillover Per Treatment Arm (Quantification 2)}

One might suggest that we should also account for the heterogeneity in the parental health spillover according to the treatment received, especially because parents are directly involved in the FT arm, but not systematically involved in TAU. ${ }^{3}$ In this case, the parameter $\widehat{\beta}_{1}^{t}$ will also vary by treatment arm. Let us consider the estimated parameter $\widehat{\beta_{1}^{t, F T}}$, where $F T=0$ when Eq. (1) is run on the sample of adolescents receiving TAU and $F T=1$ when it is run on those receiving FT. Three estimated health spillover coefficients (one for each time point) within each treatment arm can be used to quantify a utility gain for the parent, and then transformed into a QALY gain as follows:

$$
\begin{aligned}
\operatorname{QALY}_{i}^{\mathrm{Spe} 2}= & {\left[\frac{\left(\widehat{\beta_{1}^{0, F T}}+\widehat{\beta_{1}^{1, F T}}\right)}{2}\right] \times 0.5 } \\
& +\left[\frac{\left(\widehat{\beta_{1}^{1, F T}}+\widehat{\beta_{1}^{2, F T}}\right)}{2}\right] \times 0.5 \text { with } F T=\{0,1\} .
\end{aligned}
$$

\footnotetext{
3 TAU included supportive therapy/counselling (25.1\%), cognitivebehavioural therapy (17.4\%), family work $(11.5 \%)$, formal systemic FT $(10.7 \%)$ and various other therapies.
} 


\subsubsection{Absolute Health Spillover (Quantification 3)}

Considering the primary outcome of the study was reducing repetitions of self-harm over 12 months, one could argue that measuring spillover coefficients according to the final primary outcome provides an absolute health spillover for the parent. Contrary to Quantification 1, Eq. (1) is now run separately on the sub-sample of adolescents who did not have a repeated self-harm at 12 months and on those who did self-harm again. The two sets of estimated health spillover coefficients $\beta_{1}^{t, S H}$ with $S H=\{0,1\}$ are used to generate an absolute QALY gain for the parent as follows:

$$
\begin{aligned}
\operatorname{QALY}_{i}^{\mathrm{Spe} 3}= & {\left[\frac{\left(\widehat{\beta_{1}^{0, S H}}+\widehat{\beta_{1}^{1, S H}}\right)}{2}\right] \times 0.5+\left[\frac{\left(\widehat{\beta_{1}^{1, S H}}+\widehat{\beta_{1}^{2, S H}}\right)}{2}\right] } \\
& \times 0.5 \text { with } S H=\{0,1\} .
\end{aligned}
$$

\subsubsection{Absolute Global Health Spillover Per Treatment Arm (Quantification 4)}

The absolute QALY gain for the parent could additionally account for the heterogeneity in health spillover according to treatment. The health spillover is measured using the estimated coefficient $\widehat{\beta_{1}^{t, S H, F T}}$ estimating Eq. (1) on four different sub-samples of adolescents.

$$
\begin{aligned}
\mathrm{QALY}_{i}^{\text {Spec4 }}= & {\left[\frac{\left(\widehat{\beta_{1}^{0, S H, F T}}+\widehat{\beta_{1}^{1, S H, F T}}\right)}{2}\right] \times 0.5 } \\
& +\left[\frac{\left(\widehat{\beta_{1}^{1, S H, F T}}+\widehat{\beta_{1}^{2, S H, F T}}\right)}{2}\right] \times 0.5 \text { with } S H \\
= & \{0,1\} F T=\{0,1\}
\end{aligned}
$$

\subsubsection{Additive Accrued Health Benefits (Quantification 5)}

Using prior empirical studies, [20-22] health spillover could also be measured using an additive approach where the QALY gain of each individual in the dyad adolescent/ parent is independently calculated and then the two QALY gains are summed. Our case study uses two different HRQoL instruments for the adolescent and the parent. If $\mathrm{HUI}^{t}$ represents the parent's health state utility value at each time point, parent's QALYs are calculated as follows:

$\mathrm{QALY}_{i}^{\mathrm{Spec} 5}=\left[\frac{\mathrm{HUI}^{0}+\mathrm{HUI}^{1}}{2}\right] \times 0.5+\left[\frac{\mathrm{HUI}^{1}+\mathrm{HUI}^{2}}{2}\right] \times 0.5$.
It is worthwhile to note that we assume that the QALYs as generated from HUI2 or EQ-5D-3L are of the same nature and meaning, and can be summed even if they are generated for two different individuals and produced from different instruments. This assumption follows from the foundation of resource allocation decisions in health according to which QALY provides an equal valuation between individuals and healthcare interventions of health improvement, independently of the HRQoL instrument being used to measure quality of life.

\subsection{Parental Health Spillovers in Cost-Effectiveness Analysis: A New Perspective}

In addition to all possible quantification methods to account for parental health spillover outlined in the previous section, we propose an additional method. While in the context of the economic evaluation of meningitis vaccination, Al-Janabi et al. [23] proposed a unique health spillover estimate that was applied to each family member affected or a health spillover estimate according to their proximity to the patient, we believe that this would not be appropriate in our case study. Three arguments motivate our viewpoint.

First, a single utility value would deny the heterogeneity observed in parents' characteristics at baseline and their potential to benefit over the duration of the study according to their level of engagement in the treatment, whether this is FT or TAU. From a clinical viewpoint, it would be expected that FT has an impact on other members of the family irrespective of whether those members attended the therapy sessions or whether there was any change in the self-harming adolescent. If therapy leads to those attending, behaving or communicating differently, this will inevitably impact others they relate to. The magnitude and even the direction of such impacts will vary from one family member to another, but cannot be ignored. Second, the treatment arm itself might impact on the parent's health independently from the adolescent's health improvement; in the SHIFT trial, for a number of secondary outcomes, caregivers reported significantly better outcomes than the adolescents [14]. Third, as part of a trial, several repeated observations of health utilities are available and it appears important to account for all the available repeated information when quantifying spillover.

These arguments would lead us to consider the additive approach (where the QALY gain of each individual in the dyad adolescent/parent is independently calculated) appealing. At the same time, it is important to ensure that such aggregation does not lead to a decision that deteriorates the health of the adolescent, or more generally, of the patient in the first place. There are clear value judgements about the priority assigned to the identified patient, who is judged the 
Table 2 Adolescents' characteristics at baseline

\begin{tabular}{llll}
\hline Characteristics & All $(N=754)$ & TAU $(N=371)$ & FT $(N=383)$ \\
\hline Sex, $n(\%)$ & & & \\
Male & $93(12)$ & $48(13)$ & $45(12)$ \\
Female & $661(88)$ & $323(87)$ & $338(88)$ \\
Age, years, $n(\%)$ & & & \\
$11-14$ & $396(53)$ & $195(53)$ & $201(52)$ \\
$15-17$ & $358(47)$ & $176(47)$ & $182(48)$ \\
Centre, $n(\%)$ & & & \\
Yorkshire & $272(36)$ & $135(36)$ & $137(36)$ \\
Manchester & $267(35)$ & $132(36)$ & $135(35)$ \\
London & $215(29)$ & $104(28)$ & $2.60(10.95)$ \\
Total no. of self-harm episodes, mean (SD) & $2.92(21.51)$ & $3.26(28.59)$ & \\
Type of index episode, $n(\%)$ & & & $27(23)$ \\
Self-poisoning & $170(23)$ & $83(22)$ & $25(7)$ \\
Self-injury & $533(71)$ & $262(71)$ & \\
Combined & $51(7)$ & $26(7)$ & $239(62)$ \\
Source of referral (from hospital), $n(\%)$ & & & $0.68(0.28)$ \\
Yes & $274(36)$ & $130(35)$ & $7.56(4.22)$ \\
No & $480(64)$ & $241(65)$ & \\
EQ-5D-3L score (overall), mean (SD) & $0.68(0.27)$ & $0.68(0.26)$ & $7.21(4.29)$ \\
Hopelessness Scale for Children score ${ }^{\mathrm{a}}$, mean (SD) & $7.39(4.26)$ & & \\
\hline
\end{tabular}

$E Q-5 D-3 L$ EuroQoL 5 Dimensions 3 Levels, $F T$ family therapy, $S D$ standard deviation, $T A U$ treatment as usual

${ }^{a}$ Hopelessness scale score was not available for 11 adolescents

most important individual to benefit from a treatment, while the inclusion of health spillover effects for other individuals are of secondary purpose.

For this reason, we propose that health gains are aggregated at the household level if and only if the QALY gain for the patient is positive or equal to zero. When the QALY gain for the patient is positive, we need to identify a means of adjusting for the parental health spillover so that the patient's health gain remains a priority for the healthcare decisions to be made. The concept of an equivalence scale (ES) as we will refer to from now on, has been used in economics to measure social welfare and adjusts the income of all household members accounting for the size of the household and the age of its members [44-46]. In our context, an ES would allow the adjustment of all health gains for the rest of the household as an additional individual equivalent QALY or utility gain where all the household members (including the patient) are accounted for. The ES transforms a distribution of observed QALY gains across heterogeneous household members into a household health gain. This adjusted health spillover can then simply be summed to the QALY gain of the patient in the CEA.

Following Buhmann et al. [44], let us consider that $Q$ measures the adjusted health spillover as follows:

$Q=\frac{\sum_{r=1}^{R} h_{r}}{(R+1)^{a}}$ where $h_{r}$ equals the health spillover for each family relative $r$, $R$ is the number of family relatives with an observed QALY or utility gain and $a$ is the elasticity of the ES rate, which varies between 0 (when the health spillover is unadjusted and equivalent to a simple sum of the QALY gain available) and 1 (when a per capita QALY is used). The value of $a$ is defined according to the importance given to the QALY gain of the family members beyond the patient (e.g. if $a=0$, the family members are as important as the patient and this would be equivalent to quantification 5). In our alternative specifications, we consider five examples of quantification of health spillover using an ES where $a=\{0,0.3,0.5,0.8,1\}$.

\section{Results}

\subsection{Regression Models}

Descriptive statistics are presented in Table 2. At baseline, more than two thirds of the adolescents were female with about three self-harm episodes over the duration of the trial. Self-harm was caused by self-injury for over $70 \%$ of the adolescents with more than $50 \%$ reporting some problems with anxiety/depression. For parents, $86 \%$ were mothers with an average age of 42 years (see Table 3). Parent's average GHQ-12 was 8.52 (standard deviation 5.38), which is 
Table 3 Parents' characteristics at baseline

\begin{tabular}{|c|c|c|c|}
\hline Characteristics & All $(N=754)$ & TAU $(N=371)$ & $\mathrm{FT}(N=383)$ \\
\hline \multicolumn{4}{|l|}{ Sex, $n(\%)$} \\
\hline Male & 89 (12) & 47 (13) & $42(11)$ \\
\hline Female & $665(88)$ & $324(87)$ & $341(89)$ \\
\hline \multicolumn{4}{|l|}{ Relationship to adolescent, $n(\%)$} \\
\hline Father & $85(11)$ & $47(13)$ & $38(10)$ \\
\hline Foster parent & $2(0)$ & $1(0)$ & $1(0)$ \\
\hline Guardian & $11(1)$ & $3(1)$ & $8(2)$ \\
\hline Mother & $649(86)$ & $318(86)$ & $331(86)$ \\
\hline Step-father & $2(0)$ & $0(0)$ & $2(1)$ \\
\hline Step-mother & $5(1)$ & $2(1)$ & $3(1)$ \\
\hline Age $^{\mathrm{a}}$, years, mean $(\mathrm{SD})$ & $42.38(6.42)$ & $42.40(6.18)$ & $42.36(6.64)$ \\
\hline HUI score (overall), mean (SD) & $0.71(0.28)$ & $0.70(0.28)$ & $0.72(0.27)$ \\
\hline $\begin{array}{l}\text { McMaster Family Assessment Device }{ }^{\mathrm{b}} \text {, mean } \\
\text { (SD) }\end{array}$ & $2.20(0.37)$ & $2.21(0.37)$ & $2.20(0.36)$ \\
\hline Family Questionnaire $^{c}$, mean (SD) & $52.86(10.75)$ & $52.88(10.79)$ & $52.84(10.72)$ \\
\hline Parent $\mathrm{GHQ}^{\mathrm{d}}$, mean $(\mathrm{SD})$ & $5.70(4.07)$ & $6.07(4.07)$ & $5.33(4.04)$ \\
\hline
\end{tabular}

FT family therapy, GHQ General Health Questionnaire, $H U I$ Health Utility Index, $S D$ standard deviation, $T A U$ treatment as usual

${ }^{\text {a }}$ Age was not available for 81 caregivers

${ }^{\mathrm{b}}$ McMaster Family Assessment Device was not available for 9 parents

${ }^{c}$ Family Questionnaire was not available for 1 parent

${ }^{\mathrm{d}}$ Parent GHQ score was not available for 3 parents

Table 4 Adolescent's and parent's health-related quality of life by time period $(N=754)$

\begin{tabular}{llll}
\hline & Baseline & 6 months & 12 months \\
\hline Overall, mean (SD) & & $0.78(0.17)$ & $0.80(0.19)$ \\
Adolescent's EQ-5D-3L score & $0.68(0.27)$ & $0.76(0.23)$ & $0.78(0.23)$ \\
$\begin{array}{l}\text { Parent's HUI score } \\
\text { Family therapy }\end{array}$ & $0.71(0.28)$ & $0.80(0.17)$ & $0.81(0.19)$ \\
Adolescent's EQ-5D-3L score & $0.68(0.28)$ & $0.77(0.23)$ & $0.78(0.23)$ \\
$\begin{array}{l}\text { Parent's HUI score } \\
\text { Treatment as usual }\end{array}$ & $0.72(0.27)$ & $0.76(0.17)$ & $0.78(0.18)$ \\
Adolescent's EQ-5D-3L score & $0.68(0.26)$ & $0.76(0.22)$ & $0.78(0.23)$ \\
$\begin{array}{l}\text { Parent's HUI score } \\
\text { Difference FT vs. TAU, mean (SD) }\end{array}$ & $0.70(0.28)$ & $0.043^{* * *}(0.01)$ & $0.036^{* *}(0.14)$ \\
Adolescent's EQ-5D-3L score & $-0.003(0.20)$ & $0.014(0.03)$ & $0.000(0.02)$ \\
Parent's HUI score & $0.019(0.02)$ & & \\
\hline
\end{tabular}

$E Q-5 D-3 L$ EuroQoL 5 Dimensions 3 Levels, $F T$ family therapy, HUI Health Utility Index, $S D$ standard deviation, $T A U$ treatment as usual $* * p<0.01 ; * * * p<0.001$

within the distressed range (4-12) but lower than the level of psychological distress observed in a sample of caregivers of a dependent relative [47].

Table 4 shows the mean utility scores for adolescents and their parent at baseline, 6 and 12 months, overall and by treatment arm. For the adolescents, utility scores increase monotonically over the 12 months and regardless of the treatment arm. Differences in utility scores between arms were significant at 6 and 12 months favouring FT. The difference from baseline appears to be slightly larger in FT than in TAU (on average 0.145 vs. 0.095). The parent's utility also shows an increase in the overall HUI2 score at 6 and 12 months from baseline; this increase however is much smaller than for the adolescent (on average 0.045 vs. 0.12) and is not significant when distinguished by treatment arm. 
Table 5 Relative health spillover: results of Tobit regression model of the parent's health-related quality of life with adolescent's EuroQoL 5 Dimensions 3 Levels (EQ-5D-3L) score (full sample with imputations for missing data)

\begin{tabular}{|c|c|c|c|c|c|c|}
\hline \multirow[t]{2}{*}{ Variables } & \multicolumn{3}{|l|}{ Model 1} & \multicolumn{3}{|l|}{ Model 2} \\
\hline & Baseline & 6 months & 12 months & Baseline & 6 months & 12 months \\
\hline \multicolumn{7}{|l|}{ Adolescent } \\
\hline EQ-5D-3L & -0.0077 & $0.2913 * * *$ & 0.0881 & 0.0558 & $0.2997 * * *$ & $0.1272 * *$ \\
\hline Female & $0.0895^{*}$ & $0.0516^{*}$ & 0.0332 & 0.0470 & 0.0314 & 0.0136 \\
\hline Age $15-17$ years vs. $11-14$ years & -0.0231 & 0.0183 & 0.0162 & 0.0130 & 0.0078 & 0.0398 \\
\hline \multicolumn{7}{|l|}{ Type of index episode (ref. self-poisoning) } \\
\hline Self-injury & & & & 0.0336 & $0.0752 * * *$ & 0.0119 \\
\hline Combined & & & & 0.0495 & 0.0594 & 0.0078 \\
\hline Repeated SH episodes (ref. >3 events) & & & & -0.0357 & -0.0565 & 0.0263 \\
\hline Hopelessness Scale for Children score & & & & $0.0108 * * *$ & $0.0047^{*}$ & $0.0050^{*}$ \\
\hline \multicolumn{7}{|l|}{ Parent } \\
\hline McMaster Family Assessment Device & & & & $-0.1031 * *$ & $-0.0702 * *$ & $-0.0763^{*}$ \\
\hline Family Questionnaire & & & & $-0.0033 * *$ & $-0.0027 * *$ & $-0.0027^{*}$ \\
\hline Parent GHQ & & & & $-0.0378 * * *$ & $-0.0157 * * *$ & $-0.0150^{* * *}$ \\
\hline Female & $-0.1062^{* *}$ & $-0.0550^{*}$ & -0.0511 & -0.0218 & -0.0213 & -0.0101 \\
\hline \multicolumn{7}{|l|}{ Centre } \\
\hline Manchester & & & & $-0.0865 * * *$ & -0.0237 & -0.0097 \\
\hline London & & & & $-0.0781^{* *}$ & -0.0062 & 0.0045 \\
\hline Constant & $0.8176^{* * *}$ & $0.5914 * * *$ & $0.7564 * * *$ & $1.3256 * * *$ & $0.9341 * * *$ & $0.9594 * * *$ \\
\hline Sigma & 0.3382 & 0.2536 & 0.2900 & 0.2702 & 0.2267 & 0.2699 \\
\hline Observations & 754 & 754 & 754 & 731 & 731 & 731 \\
\hline Pseudo $R$-squared & 0.017 & 0.084 & 0.010 & 0.426 & 0.459 & 0.151 \\
\hline
\end{tabular}

$G H Q$ General Health Questionnaire, HUI Health Utility Index, ref. reference, $S H$ self-harm

${ }^{*} p<0.05 ; * * p<0.01 ; * * * p<0.001$

Table 5 presents the Tobit regression results of the parent's HRQoL; the association between the parent's and adolescent's health varies across time points and model specifications. We find a significant and positive association with the parent's health at 6 months and 12 months in Model 2 while in Model 1, the parent's health is positively associated with the adolescent's HRQoL at 6 months only. This is in line with prior studies on the experience of parents' caregiving for an ill child [5, 7, 48], and carers of people with mental health disorders [3].

The parent's HRQoL at every time point also appears to be negatively associated with a higher score of emotion within the family, of poor family functioning and of psychological distress as measured by GHQ-12, all three measured at baseline. The strong association between a parent's utility and GHQ12 has also been shown in other studies [49]. Furthermore, parent's health is positively and significantly associated with an adolescent's higher score of hopelessness; however, this association substantially reduces in magnitude and significance over time.

\subsection{Spillover Effects in Cost-Effectiveness Analysis}

Table 6 presents the incremental cost-effectiveness ratios (ICERs) and their respective probabilities of cost-effectiveness using the base-case analysis when only the adolescent's QALY gain is considered along with the five regressionbased alternative spillover quantifications ${ }^{4}$ and the ES-based spillover quantification with five alternative elasticity values. Costs used in the analysis are summarised in Table 10 of the "Appendix". Because we did not collect healthcare costs for the parent, we note that the costs for each ICER are strictly identical and it is only the level of QALY gain that varies.

Results from the base-case analysis indicate that adolescents in FT incurred $£ 1207$ higher costs on average and gained 0.030 extra QALYs than the adolescents in

\footnotetext{
${ }^{4}$ Quantification 1 is based on the Tobit regression results presented in Table 5. Quantification 2 is based on the Tobit regression results presented in Table 7 of the "Appendix". Quantification 3 is based on the Tobit regression results presented in Table 8 of the "Appendix". Quantification 4 is based on the Tobit regression results presented in Table 9 of the "Appendix".
} 
Table 6 Incremental costeffectiveness ratios (ICERs) with alternative spillover quantifications

\begin{tabular}{|c|c|c|c|c|}
\hline Scenario & Costs, $£(\mathrm{SE})$ & QALY (SE) & ICER (£/QALY) & $\begin{array}{l}\text { CE probabilities } \\
\text { of FT }(£ 20,000 \\
£ 30,000)^{\mathrm{a}}\end{array}$ \\
\hline \multicolumn{5}{|c|}{ Base-case analysis } \\
\hline TAU & $3750.59(198.34)$ & $0.745(0.008)$ & & \\
\hline \multirow[t]{2}{*}{ FT } & $4957.75(194.13)$ & $0.774(0.008)$ & & \\
\hline & Incremental costs & Incremental $Q A L Y$ & & \\
\hline FT vs. TAU & $1207.16^{* * *}(277.53)$ & $0.030 * * *(0.011)$ & $40,453.30$ & $(0.080-0.263)$ \\
\hline \multicolumn{5}{|c|}{ Quantification 1: Relative health spillover (Model 2, Table 5) } \\
\hline TAU & $3750.59(198.34)$ & $0.940(0.008)$ & & \\
\hline \multirow[t]{2}{*}{ FT } & $4957.75(194.13)$ & $0.970(0.008)$ & & \\
\hline & Incremental costs & Incremental $Q A L Y$ & & \\
\hline FT vs. TAU & $1207.16^{* * *}(277.53)$ & $0.030 * * *(0.011)$ & $40,453.30$ & $(0.073-0.284)$ \\
\hline \multicolumn{5}{|c|}{ Quantification 2: Relative health spillover per treatment arm (Model 2, Table 6) } \\
\hline TAU & $3750.59(198.34)$ & $1.001(0.008)$ & & \\
\hline \multirow[t]{2}{*}{ FT } & $4957.75(194.13)$ & $0.934(0.008)$ & & \\
\hline & Incremental costs & Incremental $Q A L Y$ & & \\
\hline FT vs. TAU & $1207.16^{* * *}(277.53)$ & $-0.067 * * *(0.011)$ & Dominated & $(0.000-0.000)$ \\
\hline \multicolumn{5}{|c|}{ Quantification 3: Absolute health spillover (Model 2, Table 7) } \\
\hline TAU & $3750.59(198.34)$ & $0.943(0.008)$ & & \\
\hline \multirow[t]{2}{*}{ FT } & $4957.75(194.13)$ & $0.972(0.008)$ & & \\
\hline & Incremental costs & Incremental $Q A L Y$ & & \\
\hline FT vs. TAU & $1207.16^{* * *}(277.53)$ & $0.030 * *(0.012)$ & $40,838.11$ & $(0.083-0.267)$ \\
\hline \multicolumn{5}{|c|}{ Quantification 4: Absolute health spillover per treatment arm (Model 2, Table 8) } \\
\hline TAU & $3750.59(198.34)$ & $1.056(0.019)$ & & \\
\hline \multirow[t]{2}{*}{ FT } & $4957.75(194.13)$ & $0.905(0.010)$ & & \\
\hline & Incremental costs & Incremental $Q A L Y$ & & \\
\hline FT vs. TAU & $1207.16^{* * *}(277.53)$ & $-0.150 * * *(0.021)$ & Dominated & $(0.001-0.004)$ \\
\hline \multicolumn{5}{|c|}{ Quantification 5: Additive health spillover ${ }^{b}$} \\
\hline TAU & $3750.59(198.34)$ & $1.492(0.015)$ & & \\
\hline \multirow[t]{2}{*}{ FT } & $4957.75(194.13)$ & $1.536(0.014)$ & & \\
\hline & Incremental costs & Incremental $Q A L Y$ & & \\
\hline FT vs. TAU & $1207.16^{* * *}(277.53)$ & $0.044 * *(0.020)$ & $27,166.45$ & $(0.297-0.568)$ \\
\hline \multicolumn{5}{|c|}{ Equivalence scale health spillover with $a=0$} \\
\hline TAU & $3750.59(198.34)$ & $1.492(0.015)$ & & \\
\hline \multirow[t]{2}{*}{ FT } & $4957.75(194.13)$ & $1.536(0.014)$ & & \\
\hline & Incremental costs & Incremental $Q A L Y$ & & \\
\hline FT vs. TAU & $1207.16^{* * *}(277.53)$ & $0.044 * *(0.020)$ & $27,166.45$ & $(0.279-0.539)$ \\
\hline \multicolumn{5}{|c|}{ Equivalence scale health spillover with $a=0.3$} \\
\hline TAU & $3750.59(198.34)$ & $1.351(0.013)$ & & \\
\hline \multirow[t]{2}{*}{ FT } & $4957.75(194.13)$ & $1.393(0.013)$ & & \\
\hline & Incremental costs & Incremental $Q A L Y$ & & \\
\hline FT vs. TAU & $1,207.16^{* * *}(277.53)$ & $0.042 * *(0.018)$ & $28,951.77$ & $(0.245-0.531)$ \\
\hline \multicolumn{5}{|c|}{ Equivalence scale health spillover with $a=0.5$} \\
\hline TAU & $3750.59(198.34)$ & $1.273(0.012)$ & & \\
\hline \multirow[t]{2}{*}{ FT } & $4957.75(194.13)$ & $1.313(0.012)$ & & \\
\hline & Incremental costs & Incremental $Q A L Y$ & & \\
\hline FT vs. TAU & $1207.16^{* * *}(277.53)$ & $0.040 * *(0.020)$ & $30,058.05$ & $(0.202-0.487)$ \\
\hline \multicolumn{5}{|c|}{ Equivalence scale health spillover with $a=0.8$} \\
\hline TAU & $3750.59(198.34)$ & $1.174(0.011)$ & & \\
\hline \multirow[t]{2}{*}{ FT } & $4957.75(194.13)$ & $1.212(0.011)$ & & \\
\hline & Incremental costs & Incremental $Q A L Y$ & & \\
\hline
\end{tabular}


Table 6 (continued)

\begin{tabular}{|c|c|c|c|c|}
\hline Scenario & Costs, $£(\mathrm{SE})$ & QALY (SE) & ICER (£/QALY) & $\begin{array}{l}\text { CE probabilities } \\
\text { of FT }(£ 20,000- \\
£ 30,000)^{\mathrm{a}}\end{array}$ \\
\hline FT vs. TAU & $1207.16^{* * *}(277.53)$ & $0.038 * *(0.015)$ & $31,581.72$ & $(0.169-0.475)$ \\
\hline \multicolumn{5}{|c|}{ Equivalence scale spillover with $a=1$} \\
\hline TAU & $3750.59(198.34)$ & $1.118(0.010)$ & & \\
\hline \multirow[t]{2}{*}{ FT } & $4957.75(194.13)$ & $1.155(0.010)$ & & \\
\hline & Incremental costs & Incremental $Q A L Y$ & & \\
\hline FT vs. TAU & $1207.16^{* * *}(277.53)$ & $0.037 * *(0.015)$ & $32,504.48$ & $(0.164-0.426)$ \\
\hline \multicolumn{5}{|c|}{$\begin{array}{l}C E, F T \text { family therapy, } Q A L Y \text { quality-adjusted life-year, } S E \text { standard error, } T A U \text { treatment as usual } \\
* p<0.05 ; * * p<0.01 ; * * * p<0.001\end{array}$} \\
\hline \multicolumn{5}{|c|}{$\begin{array}{l}{ }^{\mathrm{a}} \text { The cost-effectiveness probabilities of FT at } £ 20,000 \text { and } £ 30,000 \text { were estimated using the Stata com- } \\
\text { mand tsbceprob ( } \mathrm{Ng} \text { et al., } 2013 \text { [56]) }\end{array}$} \\
\hline
\end{tabular}

TAU, which is equivalent to an extra 10.95 days of perfect health annually. The ICER from this analysis ( $£ 40,453$ per QALY) is above the recommended threshold range specified for NICE decision making in England and Wales ( $£ 20,000-£ 30,000$ per QALY gain), indicating that FT is unlikely to be cost-effective. When considering the relative parental health spillover independently of the treatment arm using quantification 1 , the ICER is almost identical to the one obtained from the base-case analysis. However, when accounting for the direct involvement of the parents in the FT arm (quantification 2), parents and adolescents continue to incur higher costs on average but with 24.5 fewer days of perfect health (loss of 0.067 QALYs annually) than those in TAU and therefore indicating that FT is dominated by TAU.

The ICER remains above the nationally recommended threshold when we control for the absolute parental health spillover using the number of repeated self-harm events at 12 months ( $£ 40,838)$, implying that FT is not cost effective. If we further control for any heterogeneity in the absolute parental health spillover, FT is dominated by TAU with adolescents and parents in the FT arm incurring 54.8 fewer days of perfect health (loss of 0.150 QALYs annually) than those in the TAU arm. Any of the regression-based quantifications indicate that FT is unlikely to be cost effective. However, the ICER reduces to $£ 27,167$ per QALY when we simply sum the adolescent's and parent's QALYs (quantification 5), demonstrating a potential for FT to bring 16.1 extra days at full health annually for both the adolescent and the parent and a value within the NICE threshold range.

As expected, quantification 5 is equivalent to the quantification with an ES using an elasticity of $a=0$. The value of the elasticity $a$ directly impacts on the average QALY gains, and the higher the elasticity, the lower the cumulated QALY gain and thus the higher the ICER. For smaller values of the elasticity $a$ (less than 0.5 ), the quantifications using an ES show an ICER within the NICE cost-effectiveness range. The probability of FT to be cost effective is higher when using an ES to quantify spillover than with regression-based spillover quantifications; at $£ 20,000$ it is between 16 and $28 \%$ with an ES vs. $0-7 \%$ with regressions. At $£ 30,000$, it respectively reaches $43-54 \%$ vs. 0-28\%.

It is important to note that with any quantification method, both cost differences between FT and TAU and QALY differences are significant. The same analyses were performed on the complete case sample to test the sensitivity of the results to missing data imputations (see Table 11 of the "Appendix"). The ICER estimations for each spillover quantification are all larger (between $£ 34,071$ and $£ 45,842$ ) with broader standard deviations for both costs and QALYs. It is remarkable that the differences between quantifications present the same pattern as the main analysis.

\section{Discussion}

We showed that a parent's HRQoL is associated with the health of a self-harming adolescent. We investigated how health spillover for the parent could be included in CEA using alternative quantifications based on estimated coefficients and QALY valuations. Sensitivity analyses revealed that the valuation technique had a considerable impact on the magnitude of the QALY and could change the inference about the most cost-effective alternative in a trial. We made two propositions in this article. Proposition 1 suggests that health gains are only aggregated at the household level when the QALY gain for the patient is positive or equal to zero. Proposition 2 suggests the use of an ES to convert a distribution of observed health spillover across other household members into an extra health 
gain to be added to the patient's QALY gain. We illustrated the use of an ES with a set of alternative elasticity values. There are several advantages with the use of an ES. First, an ES has been widely used in the literature to measure household social welfare [44-46]. Second, health spillover measured either as a QALY gain from a utility score or a utility parameter generated from a regression model could be summed and transformed into an extra health gain using the ES. Third, the ES adapts to data availability and thus every family relative with observed health outcomes can be included. Finally, one could transform easily the ES to account for family members' proximity to the patient including an individual weight in the same way it is achieved with income equivalence scales. ${ }^{5}$ This methodological proposition will require further scrutiny in future research.

\subsection{Limitations}

Our study presents limitations. The trial study used two different HRQoL instruments to measure the adolescent and the parent's quality of life. For the purpose of the spillover quantification, we assumed that utilities and QALYs generated from two different generic measures were of the same nature and meaning and could be combined. However, these two measures are quite different in descriptive content and in valuation technique. While the EQ-5D covers dimensions of physical, mental and general health and is valued with Time Trade-Off, HUI2 additionally considers impairments in vision, hearing, and dexterity and is valued using standard gamble and visual analogue scaling. Research has shown a moderate level of agreement between HRQoL measures in various conditionspecific groups [50-53]. The assumption according to which the two preference-based measures can be combined in our spillover quantifications could potentially be biased. For example, if EQ-5D-3L tends to provide lower mean utility estimates than HUI2, this would imply for our study that quantification 5 and the ES quantification with $a=0$ lead to an aggregation of health gains where the parent's QALY gain from the intervention is relatively higher than for the adolescent's (patient's) QALY gain, and thus the patient is not the main beneficiary (though respecting proposition 1 ensures that the patient is the priority for the healthcare decision making). In this context, head-to-head comparisons between preference-based HRQoL instruments will be useful to develop potential measurement corrections to ensure comparability between utilities and QALYs when measuring health spillover.

Methodologically, the reverse correlation with a focus on the impact of a parent's health on an adolescent's health could have been of interest to study. Moreover, several authors $[13,17,54]$ have argued that potential healthcare

\footnotetext{
${ }^{5}$ See Table (p. 2) in the OECD note on ESs available here URL: http://www.oecd.org/eco/growth/OECD-Note-EquivalenceScales.pdf (consulted June 2018).
}

cost savings are transferred to others when treating one family member using family-based psychotherapy; it would be ideal to include the healthcare resource use of the parent had they been available in the data.

Conceptually, we investigated how social externalities such as the health effects on other individuals could be introduced into the framework of a CEA; to some extent, this questions whether a cost-utility analysis is appropriate or whether a cost-benefit analysis with distributional weights should be considered. We did not enter into this debate and assumed that a cost-utility analysis would remain the preferred method for the health spillover quantification [55].

Admittedly, our proposition to rely on an ES is a pragmatic choice. The adoption of a unique scale that would be identical for any CEA would have the advantage of facilitating the generation of evidence that is comparable between individuals and between cost-utility analyses.

\section{Conclusions}

There is no consensus on how health spillover of illness on family members or caregivers should be measured and valued for cost-effectiveness analyses. A household welfare function along with an equivalence scale could be used to adjust health spillovers and generate a health gain within the family to be added to the patient's QALY gain.

Acknowledgements We are grateful to Bryony Dawkins, John O'Dwyer, Laetitia Schmitt, Paula Boston, and participants to the LAGV International Conference in Public Economics in Aix en Provence in June and the EuHEA conference in Maastricht in 2018 for comments and feedback on an earlier version of this article. Two anonymous reviewers and the editors provided us with rich comments that helped improve the article. We thank Josephine Aikpitanyi for her help with literature references.

Author contributions ST designed the trial health economics analysis and ECS led the analysis. ST and ECS developed the framework for this research article and equally contributed in writing. DC was PI of the SHIFT trial and provided a clinical insight for the research. ST is the overall guarantor of the research in this article.

\section{Compliance with Ethical Standards}

Funding This research work was undertaken as part of the National Institute for Health Research Health Technology Assessment programme (project number: 07/33). The views expressed in this publication are those of the authors and do not necessarily reflect those of the HTA programme, NIHR, NHS, or the Department of Health. Study registration: ISRCTN 59793150.

Conflict of interest Sandy Tubeuf received funding from NIHR HTA (Grant no. 07/33/01) including support for travel conference presentation. Eirini-Christina Saloniki received funding from NIHR HTA (Grant no. 07/33/01) including support for travel and conference presentation. David 
Cottrell received funding from NIHR HTA (Grant no. 07/33/01) including travel costs for data collection and to meetings to present results.

Data availability Regarding research data, the principal investigator of the SHIFT study has agreed with the NIHR that data would not be made freely available in a repository and interested third parties can apply to the trial team for access to the Clinical Trials Research Unit, University of Leeds, Leeds LS2 9JT, UK.

Open Access This article is distributed under the terms of the Creative Commons Attribution 4.0 International License (http://creat ivecommons.org/licenses/by/4.0/), which permits unrestricted use, distribution, and reproduction in any medium, provided you give appropriate credit to the original author(s) and the source, provide a link to the Creative Commons license, and indicate if changes were made.

\section{Appendix}

See Tables 7, 8, 9, 10 and 11.

Table 7 Relative health spillover per arm: results of Tobit regression model of parent's health-related quality of life with adolescent's EuroQoL 5 Dimensions 3 Levels (EQ-5D-3L) score per treatment arm (full sample with imputations for missing data)

\begin{tabular}{|c|c|c|c|c|c|c|}
\hline \multirow[t]{2}{*}{ Variables } & \multicolumn{3}{|c|}{ Treatment as usual } & \multicolumn{3}{|c|}{ Family therapy } \\
\hline & Baseline & 6 months & 12 months & Baseline & 6 months & 12 months \\
\hline \multicolumn{7}{|l|}{ Adolescent } \\
\hline EQ-5D-3L & 0.0612 & $0.3189 * * *$ & $0.3261 * * *$ & 0.0596 & $0.3100 * * *$ & -0.0401 \\
\hline Female & 0.0563 & -0.0289 & -0.0192 & 0.0484 & $0.1131 * *$ & 0.0595 \\
\hline Age $15-17$ years vs. $11-14$ years & -0.0480 & -0.0050 & -0.0072 & 0.0245 & 0.0234 & $0.0810^{* *}$ \\
\hline \multicolumn{7}{|l|}{ Type of index episode (ref. self-poisoning) } \\
\hline Self-injury & 0.0096 & 0.0448 & 0.0263 & 0.0661 & $0.1175^{* * *}$ & 0.0123 \\
\hline Combined & 0.0563 & 0.0679 & -0.0049 & 0.0472 & 0.0691 & 0.0069 \\
\hline Repeated SH episodes (ref. $>3$ events) & -0.0290 & -0.0395 & 0.0479 & -0.0873 & $-0.0876^{*}$ & 0.0013 \\
\hline Hopelessness Scale for Children score & $0.0115 * *$ & $0.0059 *$ & $0.0102 * *$ & $0.0085^{* *}$ & 0.0033 & 0.0008 \\
\hline \multicolumn{7}{|l|}{ Parent } \\
\hline McMaster Family Assessment Device & -0.0244 & -0.0378 & -0.0112 & $-0.1892 * * *$ & $-0.1163 * *$ & $-0.1340 * *$ \\
\hline Family Questionnaire & $-0.0054 * *$ & $-0.0034 * *$ & -0.0018 & $-0.0010^{* *}$ & -0.0021 & -0.0026 \\
\hline Parent GHQ & $-0.0390 * * *$ & $-0.0176^{* * *}$ & $-0.0178^{* * *}$ & $-0.0354 * * *$ & $-0.0137 * * *$ & $-0.0102 * *$ \\
\hline Female & -0.0261 & -0.0282 & 0.0038 & -0.0310 & -0.0116 & -0.0331 \\
\hline \multicolumn{7}{|l|}{ Centre } \\
\hline Manchester & -0.0640 & -0.0081 & -0.01812 & $-0.1212 * * *$ & -0.0465 & -0.0178 \\
\hline London & -0.0726 & -0.0160 & 0.0049 & $-0.0836^{* *}$ & -0.0017 & -0.0276 \\
\hline Constant & $1.2351 * * *$ & $1.0202 * * *$ & $0.6121^{* *}$ & $1.4349 * * *$ & $0.8424 * * *$ & $1.1679 * * *$ \\
\hline Sigma & 0.2795 & 0.2348 & 0.2534 & 0.2560 & 0.2278 & 0.2576 \\
\hline Observations & 359 & 359 & 359 & 372 & 372 & 372 \\
\hline Pseudo $R$-squared & 0.407 & 0.358 & 0.246 & 0.481 & 0.439 & 0.208 \\
\hline
\end{tabular}

GHQ General Health Questionnaire, ref. reference, $S H$ self-harm

$* p<0.05 ; * *<0.01 ; * * * p<0.001$ 
Table 8 Absolute health spillover: results of Tobit regression model of the parent's health-related quality of life with adolescent's EuroQoL 5 Dimensions 3 Levels (EQ-5D-3L) score per repeated self-harm (SH) event at 12 months (full sample with imputations for missing data)

\begin{tabular}{|c|c|c|c|c|c|c|}
\hline \multirow[t]{2}{*}{ Variables } & \multicolumn{3}{|c|}{ No repeated SH at 12 months } & \multicolumn{3}{|c|}{ Repeated SH at 12 months } \\
\hline & Baseline & 6 months & 12 months & Baseline & 6 months & 12 months \\
\hline \multicolumn{7}{|l|}{ Adolescent } \\
\hline EQ-5D-3L & 0.0389 & $0.3023 * * *$ & $0.1567 * *$ & 0.0923 & $0.3763^{* * *}$ & 0.0708 \\
\hline Female & 0.0350 & 0.0240 & -0.0141 & 0.1071 & 0.0788 & 0.1515 \\
\hline Age $15-17$ years vs. $11-14$ years & -0.0026 & 0.0147 & 0.0311 & 0.0553 & -0.0049 & 0.0661 \\
\hline \multicolumn{7}{|l|}{ Type of index episode (ref. self-poisoning) } \\
\hline Self-injury & -0.0022 & $0.0571 *$ & -0.0289 & $-0.0492 *$ & $0.1263 * *$ & $0.1093^{*}$ \\
\hline Combined & 0.0186 & 0.0628 & -0.0586 & $-0.0856^{*}$ & 0.0735 & 0.1389 \\
\hline Repeated SH episodes (ref. $>3$ events) & -0.0094 & -0.0344 & 0.0486 & $-0.2188 * *$ & $-0.1219^{* *}$ & -0.0310 \\
\hline Hopelessness Scale for Children score & $0.0084 * *$ & 0.0027 & 0.0030 & $0.0179 * *$ & $0.0131 * *$ & $0.0160 * *$ \\
\hline \multicolumn{7}{|l|}{ Parent } \\
\hline McMaster Family Assessment Device & $-0.0977 * *$ & $-0.0706^{*}$ & $-0.0878^{*}$ & $-0.1269 *$ & -0.1029 & -0.0518 \\
\hline Family Questionnaire & $-0.0032 *$ & $-0.0027 *$ & -0.0017 & -0.0038 & -0.0036 & $-0.0057^{*}$ \\
\hline Parent GHQ & $-0.0346^{* * *}$ & $-0.0143 * * *$ & $-0.0123 * * *$ & $-0.0434 * * *$ & $-0.0169^{* *}$ & $-0.0148^{*}$ \\
\hline Female & -0.0309 & 0.0001 & -0.0037 & 0.0023 & -0.0826 & -0.0685 \\
\hline \multicolumn{7}{|l|}{ Centre } \\
\hline Manchester & $-0.0892 * *$ & -0.0033 & 0.0178 & -0.0492 & -0.0838 & -0.0567 \\
\hline London & $-0.0726^{* *}$ & 0.0044 & 0.0227 & -0.0856 & -0.0482 & $-0.1284^{*}$ \\
\hline Constant & $1.3282 * * *$ & $0.2900 * * *$ & $0.5891 * * *$ & $1.3456^{* * *}$ & $0.7436 * * *$ & $0.7164 * *$ \\
\hline Sigma & 0.2639 & 0.2215 & 0.2433 & 0.2730 & 0.2511 & 0.2814 \\
\hline Observations & 536 & 536 & 536 & 195 & 195 & 195 \\
\hline Pseudo $R$-squared & 0.407 & 0.376 & 0.189 & 0.526 & 0.417 & 0.273 \\
\hline
\end{tabular}

GHQ General Health Questionnaire, HUI Health Utility Index, ref. reference, $S H$ self-harm

$* p<0.05 ; * * p<0.01 ; * * * p<0.001$ 
Table 9 Absolute health spillover per arm: results of Tobit regression model of the parent's health-related quality of life with adolescent's EuroQoL 5 Dimensions 3 Levels (EQ-5D-3L) score per repeated self- harm (SH) event at 12 months and per arm treatment (full sample with imputations for missing data)

\begin{tabular}{|c|c|c|c|c|c|c|}
\hline \multirow[t]{2}{*}{ Variables } & \multicolumn{3}{|l|}{ TAU } & \multicolumn{3}{|l|}{ FT } \\
\hline & Baseline & 6 months & 12 months & Baseline & 6 months & 12 months \\
\hline \multicolumn{7}{|l|}{ No repeated self-harm } \\
\hline \multicolumn{7}{|l|}{ Adolescent } \\
\hline EQ-5D-3L & 0.0674 & 0.0878 & $0.3196 * * *$ & 0.0352 & $0.4587 * * *$ & 0.0039 \\
\hline Female & 0.0610 & 0.1585 & -0.0489 & 0.0180 & 0.0804 & 0.0309 \\
\hline Age $15-17$ years vs. $11-14$ years & -0.0393 & 0.0195 & -0.0087 & 0.0228 & 0.0207 & $0.0661 * *$ \\
\hline \multicolumn{7}{|l|}{ Type of index episode (ref. self-poisoning) } \\
\hline Self-injury & -0.0041 & $0.2310^{* * *}$ & 0.0276 & 0.0118 & 0.0620 & -0.0631 \\
\hline Combined & 0.1001 & $0.1639 *$ & -0.0320 & -0.0489 & 0.0011 & -0.0862 \\
\hline Repeated SH episodes (ref. $>3$ events) & 0.0435 & $-0.2209 * *$ & 0.0666 & -0.0537 & -0.0446 & 0.0378 \\
\hline YP Hopelessness Scale score & $0.0119 * *$ & 0.0103 & $0.0103^{* * *}$ & 0.0053 & 0.0015 & -0.0027 \\
\hline \multicolumn{7}{|l|}{ Parent } \\
\hline McMaster Family Assessment Device & -0.0160 & $-0.1997 * * *$ & -0.0114 & $-0.1765 * * *$ & -0.0762 & $-0.1493 * * *$ \\
\hline Family Questionnaire & $-0.0049 * *$ & -0.0032 & -0.0016 & -0.0011 & -0.0018 & -0.0014 \\
\hline Parent GHQ & $-0.0368 * * *$ & -0.0107 & $-0.0147 * * *$ & $-0.0321 * * *$ & $-0.0137 * * *$ & $-0.0104 * *$ \\
\hline Female & -0.0609 & -0.1393 & -0.0031 & -0.0193 & -0.0040 & 0.0034 \\
\hline \multicolumn{7}{|l|}{ Centre } \\
\hline Manchester & -0.0643 & -0.0569 & 0.0185 & $-0.1220 * * *$ & -0.0428 & 0.0120 \\
\hline London & -0.0769 & 0.0175 & 0.0461 & -0.0716 & 0.0021 & 0.0113 \\
\hline Constant & $1.1704 * * *$ & 1.5139 & $0.6429 * * *$ & $1.4540 * * *$ & $0.6033 * * *$ & $1.1036^{* * *}$ \\
\hline Sigma & 0.2746 & 0.2146 & 0.2443 & 0.2440 & 0.2098 & 0.2331 \\
\hline Observations & 270 & 270 & 270 & 266 & 266 & 266 \\
\hline Pseudo $R$-squared & 0.409 & 0.486 & 0.255 & 0.476 & 0.658 & 0.287 \\
\hline \multicolumn{7}{|l|}{ Repeated self-harm } \\
\hline \multicolumn{7}{|l|}{ Adolescent } \\
\hline EQ-5D-3L & 0.0388 & $0.6925^{* * *}$ & $0.4393 * *$ & 0.1371 & 0.0878 & -0.1647 \\
\hline Female & 0.0887 & -0.0019 & 0.1264 & 0.1378 & 0.1585 & 0.1815 \\
\hline Age $15-17$ y vs. $11-14$ y & 0.0918 & 0.0207 & -0.0065 & 0.0190 & 0.0195 & $0.1396 * *$ \\
\hline \multicolumn{7}{|l|}{ Type of index episode (ref. self-poisoning) } \\
\hline Self-injury & 0.0143 & -0.0021 & 0.0234 & $0.1809 * *$ & $0.2310 * * *$ & $0.1810^{* * *}$ \\
\hline Combined & 0.0944 & -0.0241 & 0.0527 & $0.2296^{*}$ & $0.1639 *$ & 0.1468 \\
\hline Repeated SH episodes (ref. $>3$ events) & $-0.3173 * *$ & -0.0911 & 0.0686 & -0.1710 & $-0.2209 * *$ & -0.1419 \\
\hline Hopelessness Scale for Children score & 0.0123 & 0.0128 & 0.0098 & $0.0200 *$ & 0.0103 & $0.0171 * *$ \\
\hline \multicolumn{7}{|l|}{ Parent } \\
\hline McMaster Family Assessment Device & -0.0071 & 0.0242 & 0.0267 & $-0.2147^{*}$ & $-0.1997 * * *$ & -0.0785 \\
\hline Family Questionnaire & $-0.0079 *$ & -0.0042 & -0.0024 & -0.0001 & -0.0032 & $-0.0078 * *$ \\
\hline Parent GHQ & $-0.0452 * * *$ & $-0.0212 * *$ & $-0.0256^{* *}$ & $-0.0466 * * *$ & -0.0107 & -0.0057 \\
\hline Female & 0.0489 & -0.0759 & 0.0217 & -0.1224 & -0.1393 & -0.2255 \\
\hline \multicolumn{7}{|l|}{ Centre } \\
\hline Manchester & 0.0287 & -0.1213 & -0.0984 & -0.0847 & -0.0569 & -0.0360 \\
\hline London & -0.0270 & -0.0973 & -0.1149 & -0.1304 & 0.0175 & -0.0909 \\
\hline Constant & $1.4848 * * *$ & $0.8156^{*}$ & 0.2465 & $1.4498 * * *$ & $1.5139 * * *$ & $1.4929 * * *$ \\
\hline Sigma & 0.2697 & 0.2444 & 0.2608 & 0.2632 & 0.2142 & 0.2700 \\
\hline Observations & 89 & 89 & 89 & 106 & 106 & 106 \\
\hline Pseudo $R$-squared & 0.537 & 0.532 & 0.342 & 0.600 & 0.778 & 0.382 \\
\hline
\end{tabular}

$G H Q$ General Health Questionnaire, HUI Health Utility Index, ref. reference, $Y P$

$* p<0.05 ; * * p<0.01 ; * * * p<0.001$ 


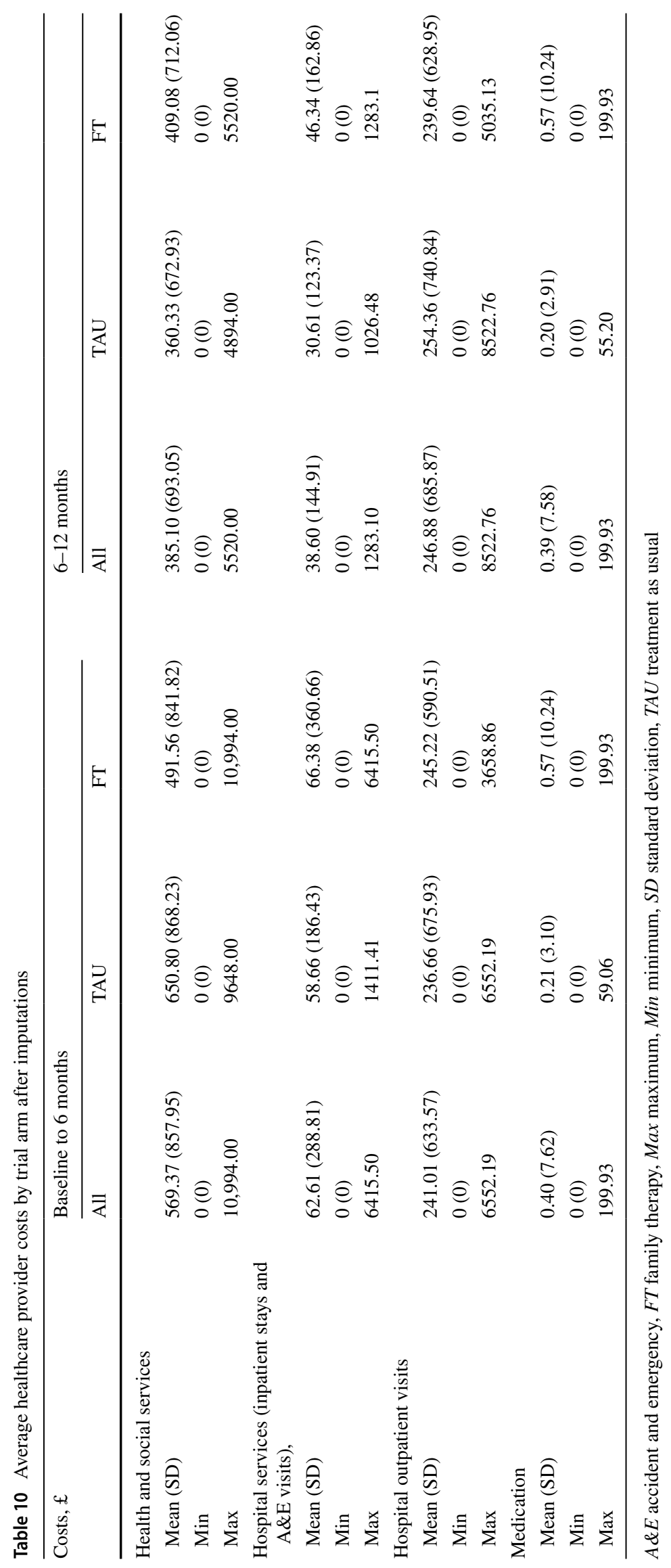


Table 11 Incremental costeffectiveness ratios (ICERs) with alternative spillover quantifications (no imputations)

\begin{tabular}{|c|c|c|c|c|}
\hline Scenario & Costs, $£(\mathrm{SE})$ & QALY (SE) & ICER (£/QALY) & $\begin{array}{l}\text { CE probabilities } \\
\text { of FT }(£ 20,000- \\
£ 30,000)^{\mathrm{a}}\end{array}$ \\
\hline \multicolumn{5}{|c|}{ Base-case analysis } \\
\hline TAU $(n=73)$ & $3475.22(380.19)$ & $0.756(0.021)$ & & \\
\hline \multirow[t]{2}{*}{ FT $(n=133)$} & $4568.081(259.32)$ & $0.779(0.016)$ & & \\
\hline & Incremental costs & Incremental $Q A L Y$ & & \\
\hline FT vs. TAU & $1092.85 * *(449.22)$ & $0.024(0.027)$ & $45,841.96$ & $(0.219-0.353)$ \\
\hline \multicolumn{5}{|c|}{ Quantification 1: Relative health spillover (Model 2, Table 5) } \\
\hline TAU $(n=73)$ & $3475.22(380.19)$ & $0.955(0.021)$ & & \\
\hline \multirow[t]{2}{*}{ FT $(n=133)$} & $4568.081(259.32)$ & $0.979(0.016)$ & & \\
\hline & Incremental costs & Incremental $Q A L Y$ & & \\
\hline FT vs. TAU & $1092.85 * *(449.22)$ & $0.024(0.027)$ & $45,841.95$ & $(0.242-0.393)$ \\
\hline \multicolumn{5}{|c|}{ Quantification 2: Relative health spillover per treatment arm (Model 2, Table 6) } \\
\hline TAU $(n=73)$ & $3475.22(380.19)$ & $1.059(0.021)$ & & \\
\hline \multirow[t]{2}{*}{ FT $(n=133)$} & $4568.081(259.32)$ & $0.882(0.016)$ & & \\
\hline & Incremental costs & Incremental $Q A L Y$ & & \\
\hline FT vs. TAU & $1092.85 * *(449.22)$ & $-0.177(0.027)$ & Dominated & $(0.000-0.000)$ \\
\hline
\end{tabular}

Quantification 3: Absolute health spillover (Model 2, Table 7)

$\begin{array}{lll}\text { TAU }(n=73) & 3475.22(380.19) & 0.955(0.021) \\ \text { FT }(n=133) & 4568.081(259.32) & 0.980(0.016) \\ & \text { Incremental costs } & \text { Incremental } Q A L Y \\ \text { FT vs. TAU } & 1092.85 * *(449.22) & 0.026(0.026)\end{array}$

Quantification 4: Absolute health spillover per treatment arm (Model 2, Table 8)

TAU $(n=73) \quad 3475.22(380.19) \quad 1.018(0.028)$

FT $(n=133) \quad 4568.081(259.32) \quad 0.920(0.017)$

Incremental costs Incremental $Q A L Y$

FT vs. TAU $1092.85 * *(449.22) \quad-0.097 * * *(0.031) \quad$ Dominated (0.001-0.000) Quantification 5: Additive health spillover ${ }^{\mathrm{b}}$

$\begin{array}{llll}\text { TAU }(n=73) & 3475.22(380.19) & 1.537(0.041) & \\ \text { FT }(n=133) & 4568.081(259.32) & 1.569(0.027) & \\ & \text { Incremental costs } & \text { Incremental QALY } & \\ \text { FT vs. TAU } & 1092.85^{* *}(449.22) & 0.032(0.047) & 34,070.62\end{array}$

Equivalence scale health spillover with $a=0$

$\begin{array}{llll}\text { TAU }(n=73) & 3475.22(380.19) & 1.537(0.041) & \\ \text { FT }(n=133) & 4568.081(259.32) & 1.569(0.027) & \\ & \text { Incremental costs } & \text { Incremental } Q A L Y & \\ \text { FT vs. TAU } & 1092.85^{* *}(449.22) & 0.032(0.047) & 34,070.62\end{array}$

Equivalence scale health spillover with $a=0.3$

\begin{tabular}{|c|c|c|c|c|}
\hline & & & & \\
\hline TAU $(n=73)$ & $3475.22(380.19)$ & $1.390(0.037)$ & & \\
\hline $\mathrm{FT}(n=133)$ & $4568.081(259.32)$ & $1.421(0.024)$ & & \\
\hline & Incremental costs & Incremental $Q A L Y$ & & \\
\hline FT vs. TAU & $1092.85 * *(449.22)$ & $0.031(0.042)$ & $35,796.37$ & $(0.337-0.455)$ \\
\hline Equivalence $s$ & e health spillover wit & $a=0.5$ & & \\
\hline TAU $(n=73)$ & $3475.22(380.19)$ & $1.308(0.034)$ & & \\
\hline $\mathrm{FT}(n=133)$ & $4568.081(259.32)$ & $1.338(0.023)$ & & \\
\hline & Incremental costs & Incremental $Q A L Y$ & & \\
\hline FT vs. TAU & $1092.85 * *(449.22)$ & $0.030(0.040)$ & $36,841.44$ & $(0.326-0.443)$ \\
\hline Equivalence s & e health spillover wit & $a=0.8$ & & \\
\hline TAU $(n=73)$ & $3475.22(380.19)$ & $1.204(0.031)$ & & \\
\hline $\mathrm{FT}(n=133)$ & $4568.081(259.32)$ & $1.233(0.021)$ & & \\
\hline & Incremental costs & Incremental $Q A L Y$ & & \\
\hline
\end{tabular}


Table 11 (continued)

\begin{tabular}{lllll}
\hline Scenario & Costs, $£(\mathrm{SE})$ & QALY (SE) & ICER (£/QALY) & $\begin{array}{l}\text { CE probabilities } \\
\text { of FT (£20,000- } \\
£ 30,000)^{\mathrm{a}}\end{array}$ \\
\hline FT vs. TAU & $1092.85^{* *}(449.22)$ & $0.029(0.036)$ & $38,251.46$ & $(0.311-0.433)$ \\
Equivalence scale spillover with $a=1$ & & & \\
TAU $(n=73)$ & $3475.22(380.19)$ & $1.146(0.030)$ & & \\
FT $(n=133)$ & $4568.081(259.32)$ & $1.174(0.020)$ & & $(0.286-0.394)$ \\
& Incremental costs & Incremental $Q A L Y$ & & $39,089.31$ \\
FT vs. TAU & $1092.85^{* *}(449.22)$ & $0.028(0.035)$ & & \\
\hline
\end{tabular}

$F T$ family therapy, $Q A L Y$ quality-adjusted life-year, $S E$ standard error, $T A U$ treatment as usual

${ }^{*} p<0.05 ; * * p<0.01 ; * * * p<0.001$

${ }^{a}$ The cost-effectiveness probabilities of FT at $£ 20,000$ and $£ 30,000$ were estimated using the Stata command tsbceprob (Ng et al., 2013 [56])

${ }^{\mathrm{b}}$ The adolescent's and parent's QALYs are summed, this is equivalent to $a=0$

\section{References}

1. Evans E, Hawton K, Rodham K. In what ways are adolescents who engage in self-harm or experience thoughts of self-harm different in terms of help-seeking, communication and coping strategies? J Adolesc. 2005;28(4):573-87.

2. Grad J, Sainsbury P. Mental illness and the family. Lancet. 1963;1(7280):544-7.

3. Shah AJ, Wadoo O, Latoo J. Quality of life for parents of children with autism spectrum disorders. Br J Med Pract. 2010;3(3):327.

4. McCrone P, Dhanasiri S, Patel A, Knapp M, Lawton-Smith S. Paying the price: the cost of mental health in England to 2026. London: The King's Fund; 2008.

5. Wittenberg E, Saada A, Posser LA. How illness affects family members: a qualitative interview survey. Patient. 2013;6:257-68.

6. Lavelle TA, Wittenberg E, Lamarand K, Posser LA. Variation in the spillover effects of illness on parents, spouses, and children of the chronically ill. Appl Health Econ Health Policy. 2014;12:117-24.

7. Kuhlthau K, Payakachat N, Delahaye J, Hurson J, Pyne JM, Kovacs E, et al. Quality of life for parents of children with autism spectrum disorders. Res Autism Spectr Disord. 2014;8:1339-50.

8. Stratton P. Report On The Evidence Base Of Systemic Family Therapy. Association for Family Therapy, UK

9. Fortune S, Cottrell D, Fife S. Family factors associated with adolescent self-harm: a narrative review. J Fam Ther. 2016;38(2):226-56.

10. Byford S, Harrington R, Torgerson D, Kerfoot M, Dyer E, Harrington $\mathrm{V}$, et al. Cost-effectiveness analysis of a home-based social work intervention for children and adolescents who have deliberately poisoned themselves: results of a randomised controlled trial. Br J Psychiatry. 1999;174:56-62.

11. Goldfield G, Epstein L, Kilanowski C, Paluch R, Kogut-Bossler B. Cost-effectiveness of group and mixed family-based treatment for childhood obesity. Int J Obesity. 2001;25(12):1843-9.

12. Flores G, Bridon C, Torres S, Perez R, Walter T, Brotanek J, et al. Improving asthma outcomes in minority children: a randomized, controlled trial of parent mentors. Pediatrics. 2009;124(6):1522-32.

13. Bodden DH, Dirksen CD, Bogels SM, Nauta MH, De Haan E, Ringrose J, et al. Costs and cost-effectiveness of family CBT versus individual CBT in clinically anxious children. Clin Child Psychol Psychiatry. 2008;13(4):543-64.

14. Cottrell D, Wright-Hughes A, Collinson M, Boston P, Eisler I, Fortune S, et al. Effectiveness and cost-effectiveness of systemic family therapy compared with treatment as usual for young people after self-harm: a pragmatic randomised controlled trial. Lancet Psychiatry. 2018;5(3):203-16.

15. Griebsch I, Coast J, Brown J. Quality-adjusted life-years lack quality in pediatric care: a critical review of published costutility studies in child health. Pediatrics. 2005;115(5):e600-14.

16. Fals-Stewart W, O'Farrell TJ, Birchler GR, Cordova J, Kelley ML. Behavioral couples therapy for alcoholism and drug abuse: where we've been, where we are, and where we're going. J Cogn Psychother. 2005;19(3):229-46.

17. Crane D. Does family therapy reduce health care costs for more than the identified patient? Clin Child Psychol Psychiatry. 2011;16(1):3-4.

18. NICE. Guide to the methods of technology appraisal. Process and methods guides. London: NICE; 2013. p. 102.

19. Wittenberg E, Posser LA. Disutility of illness for caregivers and families: a systematic review of the literature. Pharmacoeconomics. 2013;31:489-500.

20. Meeuwsen E, Melis R, van der Aa G, Goluke-Willemse G, de Leest B, van Raak F, et al. Cost-effectiveness of one year dementia follow-up care by memory clinics or general practitioners: economic evaluation of a randomised controlled trial. PLoS One. 2013;8(11):1-7.

21. Søgaard R, Sørensen J, Waldorff FB, Eckermann A, Buss DV, Phung KTT, et al. Early psychosocial intervention in Alzheimer's disease: cost utility evaluation alongside the Danish Alzheimer's Intervention Study (DAISY). BMJ Open. 2014;4:e004105.

22. Sturkenboom IHWM, Hendriks JCM, Graff MJL, Adang EMM, Munneke M, Nijhuis-van der Sanden MWG, et al. Economic evaluation of occupational therapy in Parkinson's disease: a randomized controlled trial. Move Disord. 2015;30(8):1059-67.

23. Al-Janabi H, Exel VJ, Brouwer W, Coast J. A framework for including family health spillovers in economic evaluation. Med Decis Mak. 2016;36(2):176-86.

24. Al-Janabi H, Exel VJ, Brouwer W, Trotter C, Glennie L, Hannigan $\mathrm{L}$, et al. Measuring health spillovers for economic evaluation: a case study in meningitis. Health Econ. 2016;25:1529-44.

25. Wright-Hughes A, Graham E, Farrin A, Collinson M, Boston P, Eisler I, et al. Self-Harm Intervention: Family Therapy (SHIFT), a study protocol for a randomised controlled trial of family therapy versus treatment as usual for young people seen after a second or subsequent episode of self-harm. Trials. 2015;16(1):501. 
26. Kazdin AE, Rodgers A, Colbus D. The hopelessness scale for children: psychometric characteristics and concurrent validity. J Consult Clin Psychol. 1986;54(2):241

27. Wiedemann G, Rayki O, Feinstein E, Hahlweg K. The Family Questionnaire: development and validation of a new selfreport scale for assessing expressed emotion. Psych Res. 2002;109(3):265-79.

28. Miller IW, Epstein NB, Bishop DS, Keitner GI. The McMaster family assessment device: reliability and validity. J Marital Fam Ther. 1985;11(4):345-56.

29. Goldberg D. General Health Questionnaire (GHQ-12). Windsor: Nfer-Nelson; 1992.

30. EuroQoL Group. EuroQoL: a new facility for the measurement of health related quality of life. Health Policy. 1990;16:199-208.

31. Horsman J, Furlong W, Feeny D, Torrance G. The Health Utilities Index $\left(\mathrm{HUI}^{\circledR}\right)$ : concepts, measurement properties and applications. Health Qual Life Outcomes. 2003;1(1):1.

32. Feeny D, Furlong W, Boyle M, Torrance GW. Multi-attribute health status classification systems: Health Utilities Index. Pharmacoeconomics. 1995;7(6):490-502.

33. Thorrington D, Eames K. Measuring health utilities in children and adolescents: a systematic review of the literature. PLoS One. 2015;10(8):e0135672.

34. Adlard N, Kinghorn P, Frew E. Is the UK NICE "reference case" influencing the practice of pediatric quality-adjusted lifeyear measurement within economic evaluations? Value Health. 2014;17:454-61.

35. Oluboyede $\mathrm{Y}$, Tubeuf S, McCabe C. Measuring health outcomes of adolescents: report from a pilot study. Eur J Health Econ. 2013;14(1):11-9.

36. Dolan P. Modeling valuations for EuroQol health states. Med Care. 1997;35(11):1095-108.

37. McCabe C, Stevens K, Roberts J, Brazier J. Health state values for the HUI2 descriptive system: results from a UK Survey. Health Econ. 2005;14(3):231-44.

38. Curtis L. Unit costs of health and social care. 2014. Canterbury, Kent: Personal Social Services Research Unit; 2014. http://www. pssru.ac.uk/project-pages/unit-costs/2014. Accessed 27 Aug 2018.

39. Cottrell D, Wright-Hughes A, Collinson M, Boston P, Eisler I, Fortune $\mathrm{S}$, et al. A pragmatic randomised controlled trial and economic evaluation of family therapy versus treatment as usual for young people seen after second or subsequent episodes of selfharm: the Self-Harm Intervention-Family Therapy (SHIFT) trial. Health Technol Assess. 2018;22(12):1-222.

40. Little RJ, Rubin DB. Single imputation methods. In: Little RJ, Rubin DB, editors. Statistical analysis with missing data. 2nd ed. New York: John Wiley \& Sons; 2002. p. 59-74.

41. Rubin DB. The calculation of posterior distributions by data augmentation. Comment: A noniterative sampling/importance resampling alternative to the data augmentation algorithm for creating a few imputations when fractions of missing information are modest: the SIR algorithm. J Am Stat Assoc. 1987;82(398):543-6.

42. Schafer JL. Analysis of incomplete multivariate data. London: CRC Press; 1997.
43. Bhadhuri A, Jowett S, Jolly K, Al-Janabi H. A comparison of the validity and responsiveness of the EQ-5D-5L and SF-6D for measuring health spillovers: a study of the family impact of meningitis. Med Decis Mak. 2017;37(8):882-93.

44. Buhmann B, Rainwater L, Guenther S, Timothy S. Equivalence scales, well-being, inequality, and poverty: sensitivity estimates across ten countries using the Luxembourg Income Study (LIS) database. Rev Income Wealth. 1988;34(2):115-42.

45. Chanfreau J, Burchardt T. Equivalence scales: rationales, uses and assumptions. Edinburgh:Scottish Government, 2008. http://www. scotland.gov.uk/Resource/Doc/933/0079961.pdf

46. Anyaegbu G. Using the OECD equivalence scale in taxes and benefits analysis. Econ Labour Market Rev. 2010;4:49-54.

47. Cuellar-Flores I, Sanchez-Lopez MP, Liminana-Gras RM, Colodro-Conde L. The GHQ-12 for the assessment of psychological distress of family caregivers. Behav Med. 2014;40(2):65-70.

48. Klassen A, Raina P, Reineking S, Dix D, Pritchard S, O'Donnell M. Developing a literature base to understand the caregiving experience of parents of children with cancer: a systematic review of factors related to parental health and well-being. Support Care Cancer. 2007; 15:807-18.

49. Lindkvist M, Feldman I. Assessing outcomes for cost-utility analysis in mental health interventions: mapping mental health specific outcome measure GHQ-12 onto EQ-5D-3L. Health Qual Life Outcomes. 2016;14(134):1-9.

50. Barton GR, Bankart J, Davis AC, Summerfield QA. Comparing utility scores before and after hearing-aid provision: results according to the EQ-5D, HUI3 and SF-6D. Appl Health Econ Health Policy. 2004;3(2):103-5.

51. Marra CA, Woolcott JC, Kopec JA, et al. A comparison of generic, indirect utility measures (the HUI2, HUI3, SF-6D, and the EQ-5D) and disease-specific instruments (the RAQoL and the HAQ) in rheumatoid arthritis. Soc Sci Med. 2005;60(7):1571-82.

52. McDonough CM, Grove MR, Tosteson TD, Lurie JD, Hilibrand AS, Tosteson AN. Comparison of EQ-5D, HUI, and SF-36-derived societal health state values among spine patient outcomes research trial (SPORT) participants. Qual Life Res. 2005;14(5):1321-32.

53. Polinder S, Haagsma JA, Bonsel G, Essink-Bot ML, Toet H, van Beeck EF. The measurement of long-term health-related quality of life after injury: comparison of EQ-5D and the health utilities index. Inj Prev. 2010;16(3):147-53.

54. Fals-Stewart W, Yates BT, Klostermann K. Assessing the costs, benefits, cost-benefit ratio, and cost-effectiveness of marital and family treatments: why we should and how we can. J Fam Psychol. 2005;19(1):28-39.

55. Labelle RJ, Hurley JE. Implications of basing health-care resources allocations on cost-utility analysis in the presence of externalities. J Health Econ. 1992;11:259-77.

56. Ng ESW, Grieve R, Carpenter JR. Two-stage nonparametric bootstrap sampling with shrinkage correction for clustered data. Stata J. 2013;13(1):141-64. 